\title{
Predictors for occupational injuries and diseases among commercial fishers in Finland 1996-2015
}

\author{
Kim O. Kaustell ${ }^{1}$, Tiina E.A. Mattila ${ }^{1}$, Timo Hurme ${ }^{1}$, Pekka S. Salmi ${ }^{1}$, Risto H. Rautiainen ${ }^{2}$ \\ ${ }^{1}$ Natural Resources Institute Finland, Helsinki, Finland \\ ${ }^{2}$ University of Nebraska Medical Center, Omaha, NE, United States
}

\begin{abstract}
Fishing is a hazardous occupation worldwide. Commercial fishers in Finland are an aging and diminishing population with a high injury rate. Insurance claims data for self-employed Finnish commercial fishers during the years 1996 through $2015(n=1951)$ were analysed to assess predictors for occupational injuries and diseases. Out of the available variables, fishery location, career length, and participation in the voluntary occupational health service programme were not significant predictors. Male gender (OR 2.02; 95\% Cl 1.37-2.99), Finnish mother tongue vs. Swedish (OR 1.98, 95\% Cl 1.53-2.55), and higher income levels from fishing (four income categories, OR range: 1.71-3.53) were associated with higher odds for a compensated occupational injury or disease claim among commercial fishers in the final multivariate model. The identified risk groups could be targeted for interventions, and the content of the occupational health service programme should be developed to gain protective effect.
\end{abstract}

(Int Marit Health 2017; 68, 4: 196-202)

Key words: commercial fishing, occupational safety, demographic factors

\section{INTRODUCTION}

Fishing is a hazardous occupation worldwide [1-4]. Commercial fishers in Finland are also an aging and diminishing population with a high injury rate [1]. Some preventive efforts have been developed to reduce the high rates of occupational injuries, illnesses and fatalities; most notably the national occupational health service $(\mathrm{OHS})$ programme. However, the effectiveness of this programme among Finnish fishers has not been evaluated. A previous study found that an occupational health service programme specifically designed for farmers was not protective, but rather increased the risk of occupational injury and disease claims [5]. The aim of this study was to evaluate if being a member of the voluntary-based occupational health service program reduced injury and illness claims among insured fishers. Information on risk and protective factors, such as the OHS program, may help design better targeted and more effective programmes for prevention.

\section{THE OCCUPATIONAL HEALTH SERVICE PROGRAMME}

In Finland, self-employed fishers have been able to join the OHS programme since 1984 . The programme was developed based on research conducted by the Finnish Institute of Occupational Health [6], and the programme administration is currently coordinated by the Farmers' Social Insure Institution (Finnish acronym: Mela). The services are provided by local private or municipal health care centres. Joining is voluntary and the services are partially paid by a membership fee and partially by government support. Farmers, fishers, and reindeer herders are offered the same OHS programme, which includes periodic health screenings and workplace safety assessments, as well as consultation on occupational health and safety matters. The health checks are recommended for every 1-2 years and the workplace safety assessments every 4 years. Trained professionals with experience in the respective trades con- 
duct workplace safety assessments. Several fishing experts have been trained to work with occupational health service providers conducting workplace safety checks on site.

\section{STUDY POPULATION}

This study focused on the self-employed commercial fishers insured by the Farmers Social Insurance Institution (Mela) anytime during the years 1996 through 2015. Mela administers the mandatory pension and occupational injury insurances for farmers, reindeer herders, and self-employed commercial fishers in Finland. During this period, the number of Mela-insured fishers decreased from 1380 to 576 [7]. The insurance is mandatory for self-employed fishers who have substantial (more than $3779 €$ in 2016) annual income from fishery. The Mela-insured fisher population is a subset of all commercial fishers, a total of 2473 registered commercial fishers in 2014 [8, 9]. The rest may fall below the threshold income level, fish outside the territorial waters of Finland, or have employee- or employer-based accident insurance from other sources.

\section{MATERIALS AND METHODS}

Two datasets were acquired from Mela. The first dataset comprised insurance policy history data for each commercial fisher insured for any length of time during the years 1996-2015 ( $\mathrm{N}$ for total population = 1951). This dataset included anonymised person ID, year of birth, insurance start and end years, gender, mother tongue, home county, average and latest fishery income, start (and possible end) years of enrolment into OHS, number of OHS workplace visits, and the number of compensated occupational disease and injury claims during 1996-2015.

The second dataset comprised detailed information on each fishing-related, compensated insurance claim comprising 41 occupational diseases, 801 injuries, and 11 fatalities for this population and time period. Descriptive analysis of these insurance claims data has been published earlier [1].

The two datasets were linked using the anonymized person IDs to create a dataset for statistical analysis in this study. The combined data comprised a complete record of fishing-related insurance policy and claim events for all insured Finnish commercial fishers $(N=1951)$ during the years 1996-2015. The data were further arranged into separate annual records for each fisher $(19,306$ person insurance years) to enable evaluation of the effect of the OHS membership, which could change from year to year.

Dates were available for all compensated insurance claims, but only the year of enrolment was available for enrolment into the OHS programme. In the analysis we assumed that the $\mathrm{OHS}$ membership started on January $1^{\text {st }}$ and lasted all year in the annual analysis dataset.
All compensated insurance claims that happened in fishing-related tasks and required medical care $(N=853)$ were used in the analysis. A dichotomised outcome variable 'Claim' was created to facilitate logistic regression analysis. The outcome variable received a value of ' 1 ' if the person had one or more compensated insurance claims during the observed year. Formulations of the predictor variables (potential risk factors) are presented in Table 1.

\section{DATA ANALYSIS}

The original data sets were merged and basic variable transformations and calculations were made using Microsoft Excel 2010. The data were analysed using SAS Enterprise Guide v. 7.11 software [10]. Generalized linear mixed models (SAS PROC GLIMMIX) were applied, using the binary 'claim' variable as the outcome variable. Clustering of the observations by person was taken into account by introducing person IDs as random effects in the model [11]. First, the univariate effects were examined by introducing single predictor variables into the model. Then, a full model with the whole set of predictor variables was fitted. These models were estimated using Gaussian quadrature to approximate the integrals with the Morel bias correction.

\section{RESULTS}

\section{RESULTS OF UNIVARIATE ANALYSES}

OHS membership. A total of 261 (13.8\%) fishers had sometime during their insurance period(s) joined the OHS. During membership, less than every fourth ( 62 fishers) had 1 (39), 2 (22) or 3 (1 person) workplace safety check(s) done by an authorised OHS service provider. $11.4 \%$ of all fishing-related claim incidents happened during $\mathrm{OHS}$ membership. The odds ratio for having an occupational insurance claim was slightly higher for members of the $\mathrm{OHS}$ (OR 1.02; 95\% Cl 0.73-1.43), but the difference was not significant (Table 2).

Gender. Approximately $85 \%$ of the insured fishers in the study population were male. The odds for men to have a compensated occupational injury or disease claim was more than twice as high compared to women (OR 2.33; 95\% Cl 1.57-3.45).

Mother tongue. Finland is officially a bi-lingual country with $91.7 \%$ of the population speaking Finnish and 5.5\% speaking Swedish as their first language in 2005 [12]. In the study population, the corresponding proportions were $65.9 \%$ and $34.1 \%$. The Swedish speaking part of the Finnish population is located mainly in coastal areas, where fishing has traditionally been a common occupation. The odds for a compensated claim were significantly higher for the Finnish speaking fishers (OR 1.85; 95\% Cl 1.43-2.39). 
Table 1. Predictor variables in the analysis

\begin{tabular}{|c|c|c|}
\hline Variable & Dimensions & Description \\
\hline OHS membership & $\begin{array}{l}\text { Member } \\
\text { Non-Member }\end{array}$ & $\begin{array}{l}\text { The person was insured as a fisher and was }(=1) \text { or was not }(=0) \text { a member of the voluntary OHS } \\
\text { during the observed calendar year. }\end{array}$ \\
\hline Gender & $\begin{array}{l}\text { Female } \\
\text { Male }\end{array}$ & Gender of the insured person. \\
\hline Mother tongue & $\begin{array}{l}\text { Finnish } \\
\text { Swedish }\end{array}$ & Mother tongue of the insured person. \\
\hline Fishing area & Coastal Inland & $\begin{array}{l}\text { The fishing area (sea/coastal or inland lakes) was determined based on the home region of the in- } \\
\text { sured person. Regions with coastal line were coded 'Coastal' whereas the rest were coded 'Inland'. }\end{array}$ \\
\hline $\begin{array}{l}\text { Age category } \\
\text { (years) }\end{array}$ & $\begin{array}{l}18-30 \\
31-40 \\
41-50 \\
51-60 \\
61-68\end{array}$ & $\begin{array}{l}\text { Age category of the insured person during the observed calendar year. Fishers under the age } \\
\text { of } 21 \text { years were combined with the category } 21-30 \text { years. The retirement age, at which the } \\
\text { mandatory occupational injury insurance stops, is } 68 \text { years. }\end{array}$ \\
\hline $\begin{array}{l}\text { Income category } \\
\text { (EUR) }\end{array}$ & $\begin{array}{l}\text { Below } 6000 \\
6001-10000 \\
10001-15000 \\
\text { Over } 15000\end{array}$ & $\begin{array}{l}\text { Income (from fishing) category of the insured person during the observed calendar year. The } \\
\text { category borders correspond to the quartile boundaries of all } 19306 \text { person-insurance years } \\
\text { in the model data, rounded to the closest thousand. As of } 2016 \text {, a yearly income of } 10000 \text { EUR } \\
\text { is the category border between full- and part-time fishers. }\end{array}$ \\
\hline $\begin{array}{l}\text { Experience } \\
\text { category (years) }\end{array}$ & $\begin{array}{l}0-5 \\
6-10 \\
11-15 \\
16-20 \\
21-30 \\
\text { Over } 30\end{array}$ & Length of the period from start of the fisher insurance to the observed calendar year. \\
\hline
\end{tabular}

OHS - Occupational Health Service

Fishing area. The weather and geographical conditions both offshore and on land differ between the sea and inland lake areas, and this could affect occupational injury and disease risks. The home county of 1451 (74.4\%) insured fishers has coastal line, and they are likely to fish on sea and coastal areas. The odds for having an occupational injury or disease claim were slightly, but not significantly bigger for the fishers in the inland lake (vs. coastal) areas (OR 1.13; 95\% Cl 0.87-1.47).

Age. The mean age of the fishers at the time of the occupational injury or disease incident was 47.6 years, while the mean age for all insured fishers during the studied period was 48.3 years. Compared to the youngest age class (18-30 years), no statistically significant differences in the odds of an insurance claim were found for any age category. While the odds are somewhat elevated in the age category of 31-40 years, there seems to be a non-significant decline in the odds ratio with older age categories.

Income level. The mean income from fishing during the insured career was calculated for each person. This mean income was adjusted for the number of insurance years at recorded income levels. Income values were adjusted for inflation to reflect year 2015 values. The median yearly income from fishing was $10,081 €$, with the lower quartile being $6,477 €$ and upper quartile $15,118 €$. Compared to the lowest income category, fishers in the highest income category had more than three times higher odds of an occupational insurance claim (OR 3.56; 95\% $\mathrm{Cl} 2.50-5.06$ ). Medium high and medium low income category fishers had significantly higher odds as well, over twofold (OR 2.25; $95 \% \mathrm{Cl} 1.57-3.24$ ) or close to double (OR 1.68; $95 \% \mathrm{Cl}$ 1.16-2.43), respectively.

Professional career length. Experience is likely to play a role in the risk of injuries. The mean length of work experience as an insured fisher was 14.7 years. Length of experience was calculated for each yearly observation period separately, using the years passed since being first insured as a fisher. With new or relatively new fishers (under 5 years of experience) as the reference group, only fishers in the most experienced category (over 30 years of experience) differed significantly from the least experienced group (OR 0.81; 95\% Cl 0.4-0.94).

\section{RESULTS OF MULTIVARIATE ANALYSIS}

The multivariate regression analyses were conducted in two phases, first for a full model including all available predictor variables, and then fitting a model with only those variables that were significant in the full model (Table 3).

When combined in a multivariate logistic regression full model, the associations of three out of seven predictor variables (gender, mother tongue and income) remained 
Table 2. Univariable logistic regression analysis results of predictors for compensated occupational injury and disease claims

\begin{tabular}{|c|c|c|c|c|c|}
\hline & \multirow{2}{*}{$\begin{array}{l}\text { Person insurance } \\
\text { years }\end{array}$} & \multirow{2}{*}{$\begin{array}{l}\text { Number } \\
\text { of claims }\end{array}$} & \multicolumn{3}{|c|}{ Univariable analysis } \\
\hline & & & $\begin{array}{l}\text { Estimated } \\
\text { odds ratio }\end{array}$ & $\begin{array}{l}95 \% \mathrm{Cl} \\
\text { lower limit }\end{array}$ & $\begin{array}{l}95 \% \mathrm{Cl} \\
\text { upper limit }\end{array}$ \\
\hline \multicolumn{6}{|l|}{ OHS membership } \\
\hline Member & 2203 & 97 & 1.02 & 0.73 & 1.43 \\
\hline Non-member & 17103 & 756 & \multicolumn{3}{|c|}{ Reference } \\
\hline \multicolumn{6}{|l|}{ Gender } \\
\hline Male & 16641 & 793 & 2.33 & 1.57 & 3.45 \\
\hline Female & 2665 & 60 & \multicolumn{3}{|c|}{ Reference } \\
\hline \multicolumn{6}{|l|}{ Mother tongue } \\
\hline FIN & 12403 & 646 & 1.85 & 1.43 & 2.39 \\
\hline SWE & 6903 & 207 & \multicolumn{3}{|c|}{ Reference } \\
\hline \multicolumn{6}{|l|}{ Fishing area } \\
\hline Coastal & 14529 & 628 & 0.89 & 0.68 & 1.15 \\
\hline Inland & 4777 & 225 & \multicolumn{3}{|c|}{ Reference } \\
\hline \multicolumn{6}{|l|}{ Age [years] } \\
\hline $18-30$ & 1001 & 52 & \multicolumn{3}{|c|}{ Reference } \\
\hline $31-40$ & 3219 & 177 & 1.22 & 0.76 & 1.96 \\
\hline $41-50$ & 5989 & 279 & 0.98 & 0.61 & 1.55 \\
\hline $51-60$ & 7046 & 287 & 0.80 & 0.50 & 1.26 \\
\hline$>61$ & 2051 & 58 & 0.60 & 0.35 & 1.02 \\
\hline \multicolumn{6}{|c|}{ Fishing income [EUR] } \\
\hline Over 15000 & 4856 & 344 & 3.56 & 2.50 & 5.06 \\
\hline $10001-15000$ & 4882 & 223 & 2.25 & 1.57 & 3.24 \\
\hline $6001-10000$ & 5121 & 283 & 1.68 & 1.16 & 2.43 \\
\hline Under 6001 & 4447 & 103 & \multicolumn{3}{|c|}{ Reference } \\
\hline \multicolumn{6}{|c|}{ Experience [years] } \\
\hline $0-5$ & 3426 & 143 & \multicolumn{3}{|c|}{ Reference } \\
\hline $6-10$ & 2719 & 128 & 1.15 & 0.86 & 1.53 \\
\hline $11-15$ & 2852 & 144 & 1.22 & 0.90 & 1.64 \\
\hline $16-20$ & 2908 & 136 & 1.05 & 0.76 & 1.46 \\
\hline $21-30$ & 5482 & 234 & 0.93 & 0.69 & 1.25 \\
\hline$>31$ & 1919 & 68 & 0.81 & 0.40 & 0.94 \\
\hline
\end{tabular}

$\mathrm{Cl}$ - confidence interval; OHS - Occupational Health Service

statistically significant (Table 3). The effect of male gender was slightly reduced compared to the univariate analysis, but still more than doubled the odds for an occupational injury or disease claim. The effect of mother tongue was similar to the effect found in univariate model. The effect of the income level from fishing was also similar in all models, likely corresponding to the amount of fishing activity and working hours, and thus also to the amount of time at risk for occupational injuries and diseases.

\section{DISCUSSION}

The purpose of this study was to evaluate predictors for occupational injuries and diseases among commercial fishers in Finland. The primary variable of interest was OHS membership while also considering gender, mother tongue, fishing area, age, income level and experience as a fisher. Data from the Finnish Farmers Social Insurance Institution (Mela) made this analysis possible as in addition to insurance policy and claim data, Mela also manages 
Table 3. Multivariable logistic regression analysis results of predictors for occupational injury and disease claims

\begin{tabular}{|c|c|c|c|c|c|c|c|c|}
\hline & \multirow[b]{2}{*}{$\begin{array}{l}\text { Person } \\
\text { insurance } \\
\text { years }\end{array}$} & \multirow[b]{2}{*}{$\begin{array}{l}\text { Number } \\
\text { of } \\
\text { claims }\end{array}$} & \multicolumn{3}{|l|}{ Full model } & \multicolumn{3}{|c|}{ Parsimonious model } \\
\hline & & & $\begin{array}{l}\text { Estimated } \\
\text { odds } \\
\text { ratio } \\
\end{array}$ & $\begin{array}{l}95 \% \mathrm{Cl} \\
\text { lower } \\
\text { limit } \\
\end{array}$ & $\begin{array}{l}95 \% \mathrm{Cl} \\
\text { upper } \\
\text { limit } \\
\end{array}$ & $\begin{array}{l}\text { Estimated } \\
\text { odds } \\
\text { ratio } \\
\end{array}$ & $\begin{array}{l}95 \% \mathrm{Cl} \\
\text { lower } \\
\text { limit } \\
\end{array}$ & $\begin{array}{l}95 \% \mathrm{CI} \\
\text { upper } \\
\text { limit } \\
\end{array}$ \\
\hline \multicolumn{9}{|l|}{ OHS membership } \\
\hline Member & 2203 & 97 & 1.08 & 0.79 & 1.49 & & & \\
\hline Non-member & 17103 & 756 & & Reference & & & & \\
\hline \multicolumn{9}{|l|}{ Gender } \\
\hline Male & 16641 & 793 & 2.04 & 1.37 & 3.03 & 2.02 & 1.37 & 2.99 \\
\hline Female & 2665 & 60 & & Reference & & & Reference & \\
\hline \multicolumn{9}{|l|}{ Mother tongue } \\
\hline FIN & 12403 & 646 & 1.94 & 1.47 & 2.56 & 1.98 & 1.53 & 2.55 \\
\hline SWE & 6903 & 207 & & Reference & & & Reference & \\
\hline \multicolumn{9}{|l|}{ Fishing area } \\
\hline Coastal & 14529 & 628 & 1.03 & 0.77 & 1.37 & & & \\
\hline Inland & 4777 & 225 & & Reference & & & & \\
\hline \multicolumn{9}{|l|}{ Age [years] } \\
\hline $18-30$ & 1001 & 52 & & Reference & & & & \\
\hline $31-40$ & 3219 & 177 & 1.14 & 0.70 & 1.85 & & & \\
\hline $41-50$ & 5989 & 279 & 0.94 & 0.58 & 1.54 & & & \\
\hline $51-60$ & 7046 & 287 & 0.88 & 0.53 & 1.46 & & & \\
\hline$>61$ & 2051 & 58 & 0.77 & 0.42 & 1.39 & & & \\
\hline \multicolumn{9}{|c|}{ Fishing Income [EUR] } \\
\hline Over 15000 & 4856 & 344 & 3.59 & 2.50 & 5.15 & 3.53 & 2.48 & 5.02 \\
\hline $10001-15000$ & 4882 & 223 & 2.32 & 1.62 & 3.34 & 2.33 & 1.62 & 3.33 \\
\hline 6001-10000 & 5121 & 283 & 1.70 & 1.17 & 2.46 & 1.71 & 1.18 & 2.47 \\
\hline Under 6001 & 4447 & 103 & & Reference & & & Reference & \\
\hline \multicolumn{9}{|l|}{ Experience [years] } \\
\hline $0-5$ & 3426 & 143 & & Reference & & & & \\
\hline $6-10$ & 2719 & 128 & 1.20 & 0.90 & 1.61 & & & \\
\hline $11-15$ & 2852 & 144 & 1.29 & 0.94 & 1.78 & & & \\
\hline $16-20$ & 2908 & 136 & 1.12 & 0.79 & 1.59 & & & \\
\hline $21-30$ & 5482 & 234 & 1.03 & 0.73 & 1.46 & & & \\
\hline$>31$ & 1919 & 68 & 0.71 & 0.43 & 1.16 & & & \\
\hline
\end{tabular}

$\mathrm{Cl}$ - confidence interval; OHS - Occupational Health Service

the OHS member registry for fishers. The majority of active commercial fishers are insured by Mela and were therefore included in the analysis.

The odds of having a compensated insurance claim were slightly higher for OHS members, but this result was not statistically significant. Earlier studies have shown that the OHS program designed for farmers has in fact increased the risk of occupational injury and disease claims among farmers in Finland $[5,13]$. This unexpected result may be biased as farmers self-select to join the voluntary OHS program. They are trained to detect occupational risks and file claims if injuries or diseases occur. They may also utilize health services more actively and have better access to diagnostic expertise by trained occupational health providers. The OHS program has been frequently promoted to farmers resulting in a relatively high participation rate, 35.6\% in 2002 [5]. Similar promotion has not occurred among fishers, and enrolling in the OHS program required active effort by the fishers. Previous interviews [14] have shown that many fishers do not know about the OHS programme or do not believe it would be of value to them. 
Lack of protective effect from OHS may be related to low participation rate $(13.8 \%)$ and ineffective implementation of the service indicated by: 1) workplace safety check was conducted only at 62 workplaces $(23.8 \%$ of all OHS members); 2) fishers are a small customer group for OHS, and no customized services or materials have been specifically designed for them as part of the OHS programme [14]; and 3) education for fishing experts acting as OHS consultants has been conducted only in a limited manner. All of these suggested reasons stem from commercial fishers being a small OHS client population. An OHS centre might have only few or even just one fisher as a customer, which hampers accumulation of experience concerning the special needs of a service targeting the fishers [14].

Occupational health service membership was not significant in univariable analysis, and it was also excluded from the final multivariable model, having no significant effect when controlling for other factors in the model. The final multivariate regression model showed that higher income, male gender, and Finnish (vs. Swedish) mother tongue were significantly associated with compensated occupational injury or disease claims.

The annual income is based on work effort, and therefore greater working hours are related to greater exposure time for work hazards. Longer working hours could contribute to elevated odds for insurance claims in the higher income classes, as well as greater odds of claims in men vs. women. However, recorded data on individual working hours or work division between men and women are not available for assessing these effects. In a typical Finnish fishing household the man has the main responsibility for catching fish on the sea or the lake, while the wife's work involves fish processing, selling fish products to the consumers and repairing fishing gear [15].

We found that the odds for an insurance claim were significantly higher for the Finnish speaking vs. Swedish speaking fishers. The same phenomenon has been observed among farmers in Finland $[5,13]$. It has also been reported that the Finnish speaking population has higher age-adjusted mortality rates than the Swedish speaking; higher mortality rates were found especially for alcohol related diseases, suicide, and other accidental and violent causes of death [16]. Contributing factors for this phenomenon have not been thoroughly assessed, but cultural and social factors may play a significant role.

In a previous study of the same population [1], 51\% of the fishers' injuries happened on board fishing vessels, when boarding or exiting the vessel, or on sea or lake ice (winter fishing on ice). One third of the observed fishers were inland lake fishers. The odds of an insurance claim did not differ significantly by region in the current study. There- fore the different conditions during fishing in the coastal (vs. inland lake) areas, or other factors related to geographical location (e.g. fishing methods, vessel type and size) did not alter the risk of insurance claims.

It could be expected that the odds of occupational injuries would decrease with accumulating age and experience. Our analysis did not show statistically significant effects of age or experience, with one exception: In the univariate analysis, fishers with more than 30 years of fishing experience had about $20 \%$ reduced odds of an insurance claim compared to fishers with 0 to 5 years of experience. The odds of insurance claims were elevated in age class of 31-40 years and the experience class of 11-15 years. All these effects may coincide with the need to maximize fishing activity to pay for investments made, provide for the family and to gain "fishing history", which is rewarded when applying for fishing quotas.

\section{LIMITATIONS OF THE STUDY}

The data used in this study focuses on a subset of commercial fishers. It does not cover part time self-employed fishers with annual income below $3779 €$ (year 2016 level), fish farmers or employed fishers.

The occupational injury and disease claim records included incident date but enrolling in the OHS is registered only as year. Some inaccuracy is introduced by presuming that the fisher was a member of the OHS during the whole calendar year even if enrolment (or resignation) happened mid-year.

Underreporting of especially minor injuries is common in injury and illness data collection systems, including accident insurance data. Reporting biases may result from underreporting. Misclassifications are also possible when entering data from claim forms into claims data systems. It was not possible to evaluate to what extent reporting and misclassification biases may have influenced our results.

\section{CONCLUSIONS}

Based on our findings and earlier research, the OHS programme showed no positive effect in reducing insurance claims. While compensated claims may not fully reflect the actual occupational injury and disease risk levels, it is clear that the effectiveness of the OHS system should be improved. In Denmark, OHS are compulsory for all persons working on registered fishing vessels, and $\mathrm{OHS}$ services have been suggested as a contributing factor to the decline in the number of serious accidents and improved safety culture. A board consisting of employees and ship owners is leading the occupational health services [17]. Better commitment of fishers and active dialogue between fishers, employees, fishers' trade organizations, OHS personnel, and research about occupational health problems and solutions 
could be a way to start designing more user-centred and effective services. Concerted and programmed efforts to keep occupational safety and health issues on the agenda of all interest groups would be another way to mitigate the risks involved with commercial fishing.

Fishing is typically a seasonal operation and in many cases also restricted to certain catching periods, which may lead to pressures for going out fishing also in bad weather conditions. Flexibility in fishing regulations could help reduce physical and psychological strain resulting from weather conditions. Fishers' behaviours and attitudes towards risks should be understood in relation to their past experience, traditions and way of life [4]. For many fishers, risk is an integral part of this masculine and heroic occupation. Finally, comparative socio-cultural studies should be done to assess factors that lead to reduced occupational injury and disease risk among the Swedish vs. Finnish speaking populations.

\section{ACKNOWLEDGEMENTS}

The Farmers' Social Insurance Institution (Mela) provided the data for this study. Risto Rautiainen's effort was compensated partially by the Central States Centre for Agricultural Safety and Health at University of Nebraska Medical Centre.

\section{REFERENCES}

1. Kaustell KO, Mattila TEA, Rautiainen RH. Occupational injuries and diseases among commercial fishers in Finland 1996-2015. Int Marit Health. 2016; 67(3): 163-170, doi: 10.5603/IMH.2016.0031, indexed in Pubmed: 27681217.

2. U.S. Bureau of Labor Statistics. Hours-based fatal injury rates by industry, occupation, and selected demographic characteristics, 2015. https://www.bls.gov/iif/oshcfoi1.htm\#rates (cited July 10 2017).

3. McGuinness E, Aasjord $\mathrm{H}$, Utne I, et al. Injuries in the commercial fishing fleet of Norway 2000-2011. Safety Science. 2013; 57 : 82-99, doi:10.1016/j.ssci.2013.01.008.

4. Power N. Occupational risks, safety and masculinity: Newfoundland fish harvesters' experiences and understandings of fishery risks. Health, Risk \& Society. 2008; 10(6): 565-583, doi: 10.1080/13698570802167405.
5. Karttunen JP, Rautiainen RH. Occupational injury and disease incidence and risk factors in Finnish agriculture based on 5-year insurance records. J Agromedicine. 2013; 18(1): 50-64, doi: 10.1 080/1059924X.2012.742029, indexed in Pubmed: 23301890.

6. Husman N, Notkola K, Virolainen V, et al. armers' occupational health program in Finland, 1979-1988: From research to practice. Scand J Work Environ Health. 1988; suppl. 1: 118-120. Available from https://www.sjweh.fi/download.php?abstract_id=1991\&file_nro=1.

7. Statistics of insured farm entrepreneurs at the end of year [in Finnish]. The Farmers' Social Insurance Institution Mela, Espoo, Finland 2017.www.mela.fi/en/ (June 27, 2017).

8. Official Statistics of Finland: Commercial marine fishermen. Natural Resources Institute Finland, Helsinki. http://stat.luke.fi/en/commercial-marine-fishery (July 12, 2017).

9. Official Statistics of Finland: Commercial inland fishermen. Natural Resources Institute Finland, Helsinki. http://stat.luke.fi/en/commercial-inland-fishery(July 12, 2017).

10. SAS Enterprise Guide v. 7.11 software. SAS Institute Inc., Cary, NC, USA. 2015.

11. Stroup WW. Generalized Linear Mixed Models: Modern Concepts, Methods and Applications. CRC Press, Boca Raton, FL. USA. 2013.

12. Official Statistics of Finland: Population according to language 1980 - 2015. Statistics Finland, Helsinki.http://tilastokeskus.fi/til/vaerak/2015/vaerak_2015_2016-04-01_tau_002_en.html(July 12, 2017).

13. Taattola K, Rautiainen $\mathrm{RH}$, Karttunen JP, et al. Risk factors for occupational injuries among full-time farmers in Finland. J Agric Saf Health. 2012; 18(2): 83-93, indexed in Pubmed: 22655518.

14. Kaustell KO, Mattila TEA, Rautiainen RH, Heiberg AM, Smeds P. Health, Safety and Environmental Competence Among Fishers in Botnia and Nordland. Pilot project website. http://hseforfisheries. weebly.com/ (July 19, 2017).

15. Salmi PS, Mellanoura JOK. Finnish small-scale fisheries: marginalisation or revival? In: Pascual J, Pita C, Bavinck M (eds). Small-Scale Fisheries in Europe: Status, resilience and governance. Too Big To Ignore 2017.

16. Sipilä $P$, Martikainen $P$. Language-group mortality differentials in Finland in 1988-2004: assessment of the contribution of cause of death, sex and age. Eur J Public Health. 2009; 19(5): 492-498, doi: 10.1093/eurpub/ckp074, indexed in Pubmed: 19502514.

17. Cristiansen JM, Østergaard H. Denmark: Occupational accidents and safety work in the Danish fishery - Developments and preventive measures. In: Christiansen, JM, Hovmand SR. ed. Prevention of accidents at work in Nordic fisheries - What has worked? TemaNord. 2017; 509: 55-66, doi:10.6027/TN2017-509. 